\title{
Moment and shear capacity of Ply-lam composed with plywood and structural timber under out-of-plane bending
}

\author{
Sung-Jun Pang ${ }^{1}$, Hyeon-Jeong Lee ${ }^{2}$, Seung Min Yang ${ }^{3}$, Seog Goo Kang ${ }^{3}$ and Jung-Kwon Oh ${ }^{4^{*}}$ (0)
}

\begin{abstract}
The aim of this study was to investigate the moment and shear capacity of Ply-lam which is composed with plywood and structural timber. The moment and shear capacity of Ply-lam were predicted by using prediction methodologies for typical cross-laminated timber (CLT). The predicted values by the methodologies were verified by comparison with measured capacities. Fifty-eight specimens of Ply-lam (five layers) were manufactured and half of the specimens were tested for bending (span-to-depth ratio $\left(R_{s d}\right)$ was $\left.25: 1\right)$. The other specimens were tested for rolling shear $\left(R_{s d}\right.$ was 12:1) in accordance with EN 16351. The results show that typical prediction methods for structural properties of CLT can also be used to predict those of Ply-lam, since the measured values were higher than the predicted values. In rolling shear test, $52 \%$ specimens failed by bending at the bottom layer. This indicates that the rolling shear test method in EN 16351 was not suitable for Ply-lam because the typical CLT would be reinforced by replacing the cross layer with plywood. Thus, the span-to-depth ratio needs to be reduced for hybrid CLT like Ply-lam.
\end{abstract}

Keywords: Moment capacity, Shear capacity, Ply-lam, Plywood, Structural timber, Cross-laminated timber

\section{Introduction}

The development of cross-laminated timber (CLT) allowed the modern timber construction system more simple and competitive $[1,2]$. CLT has an odd number of layers stacked and the even layers crossed orthogonally [3-5]. The even layers can be glued with adjacent layers and a layer composes with several lumbers. In general, the structural lumbers are not glued on their edges within layers [6-8].

Nairn [8] defined the non-glued edges as a "pre-cracks" and investigated the effects of the pre-cracks and additional cracks due to the shrinkage of CLT panel. The use of thick timber in CLT promotes cracking comparing to that of thinner timber $[9,10]$. The cracks reduce shear strength and stiffness, and may result in excessive creep

\footnotetext{
${ }^{*}$ Correspondence: jungoh@snu.ac.kr

${ }^{4}$ Research Institute of Agriculture and Life Sciences/Department of Forest Sciences, Seoul National University, Gwanak-ro 1, Gwanak-gu, Seoul, Republic of Korea

Full list of author information is available at the end of the article
}

[7]. Because the cracks change the structural properties of CLT, they must be considered for the durability analysis of CLT. Plywood is a wide panel product and has a better dimensional stability than solid wood. It has much smaller possibility to generate cracks in use. Thus, this concern in long-term behavior can decrease if a single plywood is used instead of solid wood in the even layers; this panel called as a Ply-lam.

Choi et al. [11] developed the Ply-lam because too much high-quality timber was used for manufacturing a CLT, given that small diameter of tree are supplied from most Korean forests. Due to the lower price of plywood than solid wood, the manufacturing cost of typical CLT can be reduced by replacing the cross layer of CLT with plywood. Moreover, fireproof plywood can be used to improve fire capacity of typical CLT.

The dimensional stability and thermal properties of Ply-lam were investigated. Choi et al. [12] compared the dimensional stability of Ply-lam with CLT by measuring the swelling and shrinkage depending on the
Springer Open (c) The Author(s) 2019. This article is licensed under a Creative Commons Attribution 40 International License, which permits use, sharing, adaptation, distribution and reproduction in any medium or format, as long as you give appropriate credit to the original author(s) and the source, provide a link to the Creative Commons licence, and indicate if changes were made. The images or other third party material in this article are included in the article's Creative Commons licence unless indicated otherwise in a credit line to the material. If material is not included in the article's Creative Commons licence and your intended use is not permitted by statutory regulation or exceeds the permitted use, you will need to obtain permission directly from the copyright holder. To view a copy of this licence, visit http://creativeco mmons.org/licenses/by/4.0/. 
moisture contents. When the Ply-lam and general CLT were immerged in water $72 \mathrm{~h}$, the swelling at Ply-lam and CLT was $2.37 \%$ and $2.71 \%$, respectively. Chang et al. [13] measured the thermal conductivity of Ply-lam and CLT. They showed that the thermal conductivity of Plylam was $0.163 \mathrm{~W} / \mathrm{mK}$, and lower than that of typical CLT $(0.170 \mathrm{~W} / \mathrm{mK})$. The reason seems to be the lower thermal conductivity of plywood $(0.154 \mathrm{~W} / \mathrm{mK})$ than solid wood (larch, $0.170 \mathrm{~W} / \mathrm{mK}$ ). As the previous researches show, the dimensional stability and thermal performance of Ply-lam was better than typical CLT.

To use the typical CLT as a structural element in building, the bending and shear test method and configurations were established in CLT test standard [14]. Several researchers evaluated the structural properties of CLT according to the CLT test standard. Sikora et al. [15] evaluated the bending stiffness, moment capacity, and shear capacity of CLT made from Sitka spruce. The span-to-depth ratio for shear and moment capacity was 12:1 and 24:1, respectively. Pang and Jeong [16] also evaluated the same properties of CLT from larch and pine species with the same test configurations. He et al. [17] evaluated the moment capacity of CLT from Canadian hemlock and the span-to-depth ratio was approximately 30:1. As a result, the dominant failure mode for shear test specimens was rolling shear failure in the middle transverse layer, and the failure mode for bending test was the bending failure in the bottom layer. This indicates that the failure mode of CLT was significantly affected by the span-to-depth ratio. Thus, the test method and configuration to derive structural properties should be carefully decided. The test configurations for hybrid CLT like Ply-lam, especially, span-to-depth ratio, have never been reported.

The reference design values for American CLT standard, ANSI/APA PRG 320 [18], were developed from the reference design values for structural timber in National Design Specification for Wood Construction (NDS) [19]. Since the CLT is manufactured by gluing the lamina layers, the structural properties of CLT can be predicted from the properties of lamina layers. Several methods were developed to predict the three structural properties for CLT slab design, bending stiffness, moment capacity and shear capacity. Gamma theory and shear analogy were adopted in Eurocode 5 and in American CLT standard [20], respectively. In addition, Blass and Fellmoser [21] applied composite theory to predict the properties of CLT. The researchers mentioned above [15-17] and Christovasilis et al. [22] showed that these methods were suitable for predicting the structural properties of CLT by comparing with experimental test data. The existing methods need to be validated whether they can be used in hybrid CLT.
As mentioned above, for using the Ply-lam as a slab element, the structural properties should to be evaluated according to the suitable test configuration. In this study, the bending stiffness, moment capacity, and shear capacity of Ply-lam were evaluated according to the CLT test standard due to the lack of test configurations for hybrid CLT. In addition, the prediction method for CLT was applied to Ply-lam to predict the structural properties, and the predicted values were validated by experimental data.

\section{Materials and methods \\ Plywood}

The modulus of elasticity (MOE) of plywood was measured to predict the moment capacity of Ply-lam. The size of specimen was $24 \mathrm{~mm}$ (thickness) $\times 50 \mathrm{~mm}$ (width) $\times 626 \mathrm{~mm}$ (length). Five specimens were randomly selected from plywood panel (9-ply, $1220 \mathrm{~mm}$ by $2440 \mathrm{~mm}$ ). The MOE of plywood in strong axis (the direction of outer layer was parallel to grain) was measured by a center point loading test using a universal test machine (Tinius Olsen Ltd., H50K-ST, Redhill, England) according to ASTM D143 [23]. The span length between supports was $500 \mathrm{~mm}$ and the loading rate was $10 \mathrm{~mm} /$ min. The MOE of plywood was calculated using Eq. 1:

$$
\mathrm{MOE}_{\text {plywood }}=\frac{\left(P_{2}-P_{1}\right) L^{3}}{4 w h^{3}\left(d_{2}-d_{1}\right)},
$$

where $\mathrm{MOE}_{\text {plywood }}$ is the modulus of elasticity of plywood (MPa); $P_{1}$ and $P_{2}$, the loads corresponding to $10 \%$ and $40 \%$ of the ultimate load $P_{\max }$, respectively $(\mathrm{kN}) ; L$, span of specimen $(\mathrm{mm}) ; w$, width of specimen $(\mathrm{mm}) ; h$, thickness of specimen $(\mathrm{mm}) ; d_{1}$ and $d_{2}$, the deflections corresponding to $P_{1}$ and $P_{2}$, respectively $(\mathrm{mm})$.

\section{Ply-lam \\ Specimens}

Ply-lam (5 layers) specimens were manufactured with plywood and structural timber. Figure 1 shows the composition of layers and a picture of the manufactured Plylam specimen. Larch species (Larix kaempferi Carr.), No. 3 visual grade according to NIFoS \#2018-8 [24], was used as a structural timber. The thickness was $25 \mathrm{~mm}$ and the moisture contents (MC) was $12 \pm 2 \%$. No. 1 grade of larch plywood (MC: $7 \pm 1 \%$ ) was used in plywood layer and the thickness was $24 \mathrm{~mm}$. The five layers were glued by using phenol resorcinol formaldehyde resin (PRF resin) adhesive. The glue spread was $200 \mathrm{~g} / \mathrm{m}^{2}$ and the stacked five-layer $(1220 \mathrm{~mm}$ by $3600 \mathrm{~mm}$ ) was pressed under a pressure of $0.8 \mathrm{MPa}$ for $8 \mathrm{~h}$. The manufactured Ply-lam panel was cut by $300 \times 1560 \mathrm{~mm}$ for shear test, and $300 \times 3120 \mathrm{~mm}$ for bending test. Twenty-nine specimens 


\begin{tabular}{|l|}
\hline $25 \mathrm{~mm}$ thick structural lumber (No.3 grade) \\
\hline $24 \mathrm{~mm}$ thick plywood (No.1 grade) \\
\hline $25 \mathrm{~mm}$ thick structural lumber (No.3 grade) \\
\hline $24 \mathrm{~mm}$ thick plywood (No.1 grade) \\
\hline $25 \mathrm{~mm}$ thick structural lumber (No.3 grade) \\
\hline \\
$300 \mathrm{~mm}$
\end{tabular}

a Layup of Ply-lam

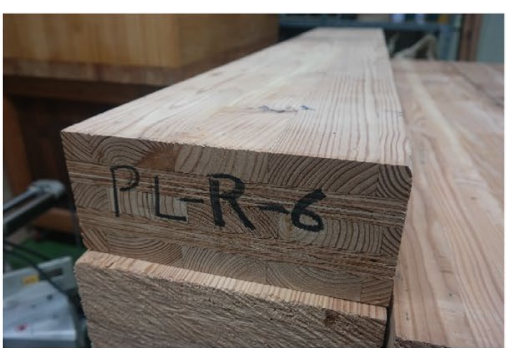

b Manufactured Ply-lam

Fig. 1 Layup and Ply-lam

for bending strength and MOE distribution were prepared. For shear strength distribution, 29 specimens were also prepared.

\section{Test configurations}

To measure the bending and shear properties of Ply-lam, two-point loading test was carried out in accordance with EN 16351 [14]. Figure 2a shows a shear test configuration and the span-to-depth ratio $\left(R_{\mathrm{sd}}\right)$ was $12: 1$. Figure $2 \mathrm{~b}$ shows a bending test configuration and $R_{\mathrm{sd}}$ was 25:1.

Load was applied at a constant displacement rate for shear test $(4 \mathrm{~mm} / \mathrm{min})$ and bending test $(6 \mathrm{~mm} / \mathrm{min})$ using a universal test machine (Zwick GmbH \& Co., Ltd., Ulm, Germany) so that the specimens failed within 4-5 min. To derive the effective bending stiffness $\left(E I_{\text {eff }}\right)$ of specimens, local deflection (shear-free, $\Delta d$ ) was measured in bending test (Fig. 2b). The spans $\left(l_{1}\right)$ for measuring $\Delta d$ was 5 times

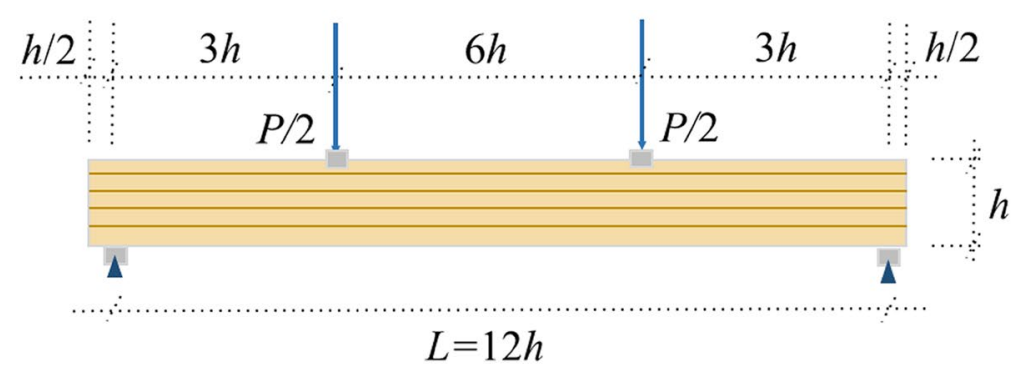

a Shear test (span-to-depth ratio was 12: 1)

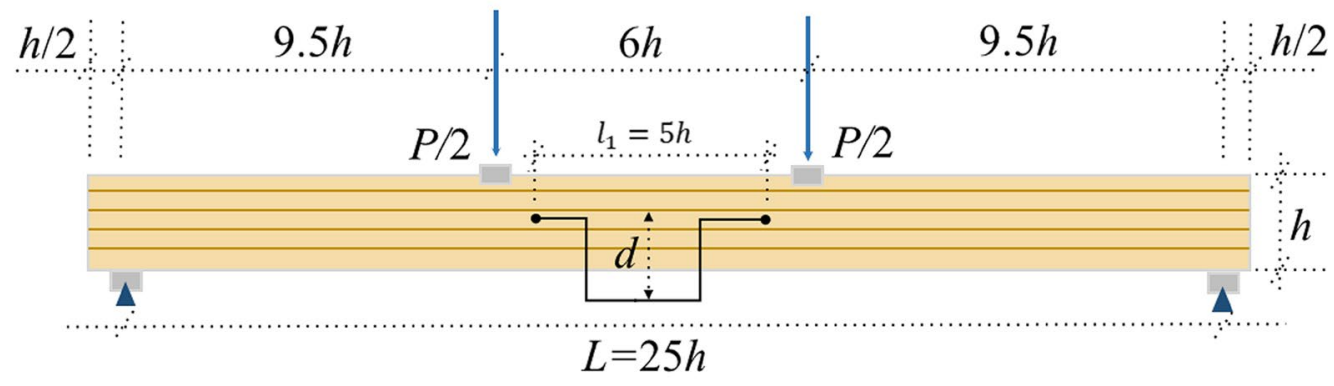

b Bending test (span-to-depth ratio was 25: 1)

Fig. 2 Test configuration for measuring shear and bending properties. $h$ thickness of specimen $(\mathrm{mm}), P$ load $(\mathrm{N}), L$ span of specimen $(\mathrm{mm})$ 
the thickness of the specimen, and the displacement was recorded by using LVDT (Zwick GmbH \& Co., Ltd., Germany) with the applied load at same time. A steel plate, $100 \mathrm{~mm}$ (width) $\times 300 \mathrm{~mm}$ (length) $\times 10 \mathrm{~mm}$ (thickness), was used under the each load point to prevent a bearing failure of specimen from the concentrated load.

\section{Characteristic values}

Bending stiffness From the experimental test, bending stiffness of each specimen was calculated by using Eq. 2 with measured load and deflection based on EN 408 [25]:

$$
E I_{\text {measured }}=\frac{L_{e} \cdot(5 h)^{2}\left(P_{2}-P_{1}\right)}{16\left(d_{2}-d_{1}\right)},
$$

where $E I_{\text {measured }}$ is measured bending stiffness of specimen $\left(\mathrm{N} \mathrm{mm}^{2}\right) ; L_{e}$, the distance between the load position and support position $(\mathrm{mm}) ; h$, the thickness of specimen (mm); $P_{1}$ and $P_{2}$, the loads corresponding to $10 \%$ and $40 \%$ of the ultimate load $P_{\max }$, respectively $(\mathrm{kN})$; and $d_{1}$ and $d_{2}$, the deflections corresponding to $P_{1}$ and $P_{2}$, respectively $(\mathrm{mm})$.

The measured bending stiffness $\left(E I_{\text {measured }}\right)$ was compared with predicted bending stiffness $\left(E I_{\text {predicted }}\right)$. Equation 3 for $E I_{\text {predicted }}$ was based on transformed section method. In this study, although the plywood was composed of 9 veneers, the veneers in plywood were very thin $(2.7 \mathrm{~mm})$ compared to solid wood layer $(25 \mathrm{~mm})$. Thus, modulus of elasticity $(E)$ for plywood was measured by Eq. 1 and the measured value was applied for plywood layers. The gross section properties, moment of inertia $(I)$ and cross-sectional area $(A)$, of plywood were applied for plywood layer in Ply-lam specimen:

$$
E I_{\text {predicted }}=\sum_{i=1}^{n}\left(E_{i} \cdot I_{i}+E_{i} \cdot A_{i} \cdot z_{i}^{2}\right)
$$

where $E I_{\text {predicted }}$ is bending stiffness predicted by transformed section method $\left(\mathrm{N} \mathrm{mm}^{2}\right) ; E_{i}$, modulus of elasticity of $i$ th layer (MPa); $I_{i}$, moment of inertia of $i$ th layer $\left(\mathrm{mm}^{4}\right) ; A_{i}$, cross-sectional area of $i$ th layer $\left(\mathrm{mm}^{2}\right)$; and $z_{i}$, distance between the center point of $i$ th layer and the neutral axis $(\mathrm{mm})$.

Moment capacity From the experimental test, moment capacities of specimens were calculated by using Eq. (4):

$$
M_{\text {measured }}=P_{\max } \cdot a,
$$

where $M_{\text {measured }}$ is the measured moment capacity $(\mathrm{kN} \mathrm{m}) ; P_{\max }$, the maximum load $(\mathrm{kN})$; and $a$, the distance between the load position and support position $(\mathrm{mm})$.

Moment capacities of Ply-lam were predicted by using Eq. (5). It was assumed that the maximum stress occurs at the surface of the specimen (Fig. 3). Two bending strength values were applied as a bending strength of the first layer. First value was from allowable bending stress in standard [26]. Second value was from in-grade test data by Park et al. [27]:

$$
M_{\text {predicted }}=\sigma_{\text {bending }} \times \frac{2 \cdot E I_{\text {predicted }}}{E_{1} h},
$$

where $M_{\text {predicted }}$ is predicted moment capacity $(\mathrm{kN} \mathrm{m})$; $\sigma_{\text {bending, bending strength of first (outermost) layer }}$ $(\mathrm{MPa}) ; E I_{\text {predicted }}$, bending stiffness predicted by transformed section method $\left(\mathrm{N} \mathrm{mm}^{2}\right) ; E_{1}$, modulus of elasticity of first (outermost) layer (MPa); and $h$, entire thickness of specimen $(\mathrm{mm})$.

Shear capacity Shear capacities of specimens were calculated by using Eq. (6):

$$
V_{\text {measured }}=P_{\max } / 2
$$

where $V_{\text {measured }}$ is the measured shear capacity $(\mathrm{kN})$; and $P_{\text {max }}$, the maximum load $(\mathrm{kN})$.

The layer at the neutral line was structural timber layer. The longitudinal shear strength of structural timber will be significantly higher than the rolling shear strength of plywood. Thus, it was assumed that the shear capacity of Ply-lam is governed by the rolling shear strength of plywood. From a conservative point of view, the maximum

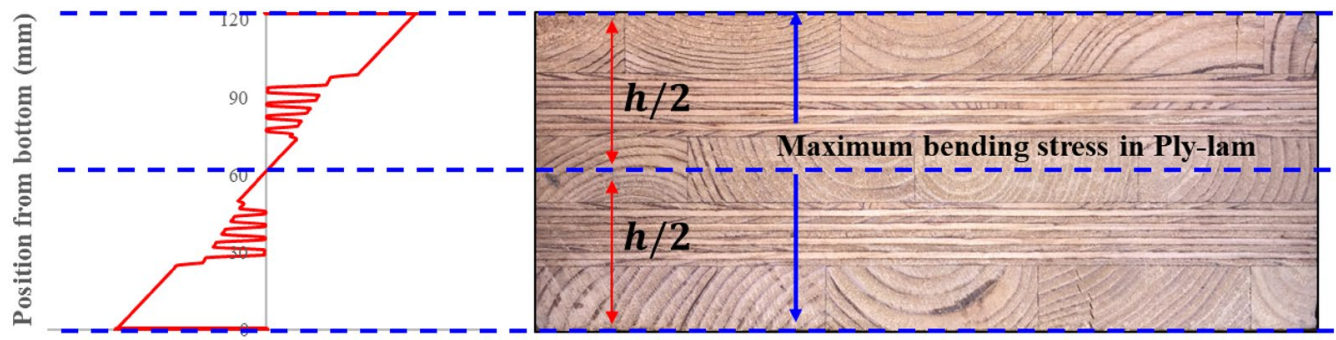

Fig. 3 Bending stress distribution to predict moment capacity of Ply-lam 
shear stress was assumed to occur at the axis just above the middle layer (Fig. 4). The shear capacity of Ply-lam can be expressed as shown in Eq. (7). The static moment of area was calculated for an axis just above the middle layer of Ply-lam, except for the middle layer. Two rolling shear strength values were applied as a rolling shear strength of plywood layer. First value was from allowable bending stress in standard [26]. Second value was from experimental test data in $\mathrm{Oh}[28]$.

$$
V_{\text {predicted }}=\tau \times \frac{E I_{\text {predicted }}}{\sum_{i=1}^{2}\left(E_{i} h_{i} Z_{i}\right)},
$$

where $V_{\text {predicted }}$ is the predicted shear capacity $(\mathrm{kN})$; $\tau$, rolling shear strength of plywood $(\mathrm{MPa}) ; E I_{\text {predicted }}$, bending stiffness measured by transformed section $\left.(\mathrm{N} \mathrm{mm})^{2}\right) ; E_{i}$, modulus of elasticity of $i$ th layer $(\mathrm{MPa}) ; h_{i}$, thickness of $i$ th layer $(\mathrm{mm})$; and $z_{i}$, distance between the center point of $i$ th layer and the neutral axis $(\mathrm{mm})$.

\section{Results and discussion}

\section{Material properties of lamina}

In case of typical CLT, the moment and shear capacity of CLT are predicted from the reference properties of layers in standard [20]. To investigate the accuracy of prediction for the moment and shear capacity of Ply-lam from the reference properties in standard, the properties of layers were prepared from both standards and experimental test.

Table 1 shows the materials properties of layer for predicting the moment and shear capacity. To predict the moment capacity of Ply-lam, MOE of each layer and bending strength of outer layer (timber) are required. The MOE for No. 3 grade larch timber was $9300 \mathrm{MPa}$ [26]. The reference MOE for No. 1 plywood was $5500 \mathrm{MPa}$. However, this value is for general species. Due to the lack of the MOE for larch plywood, the MOE of the plywood used for manufacturing Ply-lam was measured in this study. The measured MOE for No. 1 grade larch plywood was $6800 \mathrm{MPa}$.
Table 1 Materials of layer for Ply-lam

\begin{tabular}{|c|c|c|}
\hline & $\begin{array}{l}\text { Timber (No. } 3 \\
\text { grade) }\end{array}$ & $\begin{array}{l}\text { Plywood } \\
\text { (No. } 1 \\
\text { grade) }\end{array}$ \\
\hline Density $\left(\mathrm{kg} / \mathrm{m}^{3}\right)$ & $570^{\mathrm{a}}$ & $650^{\mathrm{a}}$ \\
\hline Modulus of elasticity (MOE, MPa) & $9300^{b}$ & $6800^{a}$ \\
\hline \multicolumn{3}{|l|}{ Bending strength $(\mathrm{MPa})$} \\
\hline From Korean Design Standard & $7.1^{c}$ & \\
\hline From experimental data & $19.5^{d}$ & \\
\hline \multicolumn{3}{|l|}{ Rolling shear strength (MPa) } \\
\hline From Korean Design Standard & & $1.3^{\mathrm{e}}$ \\
\hline From experimental data & & $1.5^{f}$ \\
\hline
\end{tabular}

a Average value of measured data in this study

b Reference value of No. 3 visual grade timber in standard [26]

c $2.1 \times$ allowable bending strength of No. 3 visual grade timber ( $3.4 \mathrm{MPa}$ ) in standard [26]

d 5 th percentile value of No. 3 visual grade timber by structural-size test [27]

e $3.15 \times$ rolling shear allowable strength of No. 1 plywood (0.4 MPa) in standard [26]

$f$ th percentile of rolling shear strength for plywood from experimental test data [28]

The reference bending strength for No. 3 grade larch was 3.4 MPa in standard. This value was allowable stress. Thus, the bending strength was multiplied by 2.1 to predict the moment capacity of Ply-lam according to the CLT standard [18], and it became 7.1 MPa. Park et al. [27] carried out the 4 point full-scale bending test for the No. 3 grade larch, the experimentally measured 5th percentile value was $19.5 \mathrm{MPa}$. The number of tested specimens was 213; the experimentally measured bending strength was approximately 2.7 times higher than the bending strength from standard. This indicates that the reference values in standard were conservatively decided in terms of safe design.

To predict the shear capacity of Ply-lam, rolling shear strength of middle layer (plywood) is required. The reference rolling shear strength of Ply-lam was $0.4 \mathrm{MPa}$, and this is also allowable stress. Thus, the rolling shear

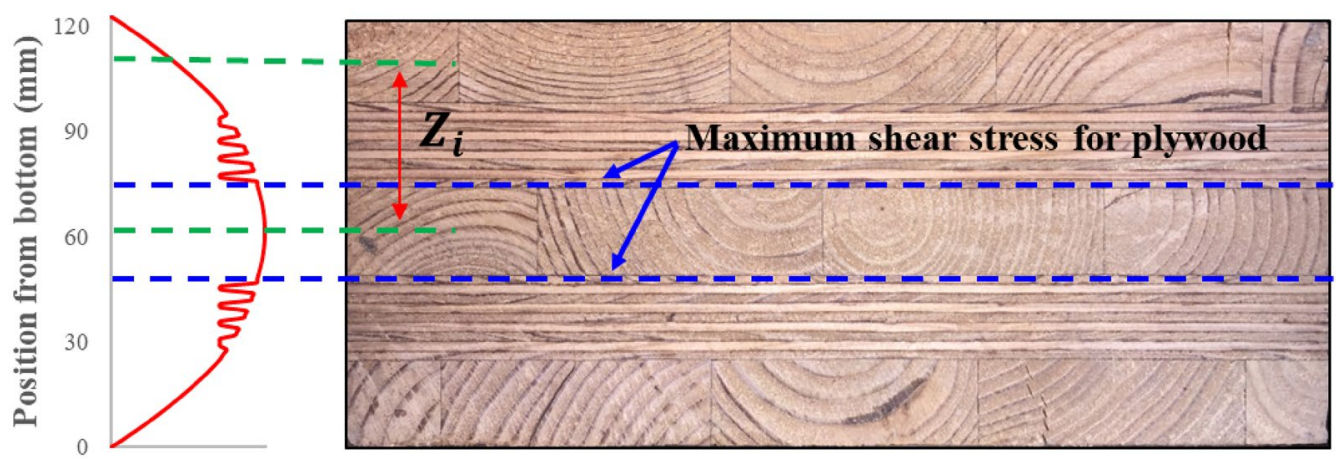

Fig. 4 Shear stress distribution to predict moment capacity of Ply-lam 
strength was multiplied by 3.15 to predict the shear capacity of Ply-lam according to the CLT standard [18], and it became 1.3 MPa. Oh [28] carried out the rolling shear strength test for the No. 1 grade larch plywood, the measured 5th percentile value was $1.5 \mathrm{MPa}$. The number of tested specimens was 15 ; the experimentally measured rolling shear strength was approximately 1.1 times the rolling shear strength from standard. The rolling shear strength of plywood from standard was not significantly different from the experimentally measured data.

\section{Moment capacity of Ply-lam}

To measure the moment capacity of Ply-lam, the Ply-lam was tested according to the CLT bending test configuration in EN 16351 [14]. Table 2 shows the configuration of specimen and failure modes for the bending test. Figure 5 shows the failure of Ply-lam in the bending test. For bending specimen with $R_{\text {sd }}$ of $25: 1$, bending failure happened at the bottom layer for all specimens. This shows that the bending test configuration for CLT was also suitable to measure the bending properties of Ply-lam.

Predicted bending stiffness and moment capacity of Ply-lam were compared with measured values. Table 3 shows the measured and predicted bending properties. In case of bending stiffness, the measured bending stiffness $\left(E I_{\text {measured }}\right)$ was $0.48 \times 10^{12} \mathrm{~N} \mathrm{~mm}^{2}$ and $16.7 \%$ higher than the predicted bending stiffness $\left(E I_{\text {predicted }}\right.$, $0.40 \times 10^{12} \mathrm{~N} \mathrm{~mm}^{2}$ ). The structural timber used in this study was visually graded by checking the defects on the timber. The MOE of timber was not controlled in grading. The predicted value was between the lowest value $\left(0.37 \times 10^{12} \mathrm{~N} \mathrm{~mm}^{2}\right)$ and the mean value of measured bending stiffness. Given that the design values are conservatively determined, this shows the prediction method in this study was suitable for Ply-lam.

In case of strength properties for structural timber, 5th percentile value is used as a characteristic value (design value) [29-31]. Since the bending strength of layers in Ply-lam is represented by 5 th percentile value, the 5 th percentile moment capacity of Ply-lam was predicted from the 5th percentile bending strength of layer. The 5th percentile value of moment capacity of Ply-lam was also experimentally derived from the 29 specimens.

Figure 6 shows the measured moment capacity values ( $\left.M_{\text {measured }}\right)$ and the predicted values $\left(M_{\text {predicted }}\right)$. The first predicted value from reference bending strength in standard $\left(M_{\text {predicted,standard }}\right)$ was $5.2 \times 10^{6} \mathrm{~N} \mathrm{~mm}$. The second predicted value from experimental 5 th percentile value $\left(M_{\text {predicted,experiment }}\right)$ was $13.7 \times 10^{6} \mathrm{~N} \mathrm{~mm}$. The 5 th percentile value of measured value $\left(M_{\text {measured }}\right)$ was $14.6 \times 10^{6} \mathrm{~N} \mathrm{~mm}$, and $64.4 \%$ and $6.2 \%$ higher than the two predicted values, respectively. Since the reference bending strength of the structural timber in standard was established conservatively in a safe way for structural member, the predicted value from reference value was quite lower than the measured value. The $6.2 \%$ difference between the predicted value from experimental value $\left(M_{\text {predicted,experiment }}\right)$ and $M_{\text {measured }}$ shows that the prediction method in this study was quite reasonable to predict the moment capacity of Ply-lam.

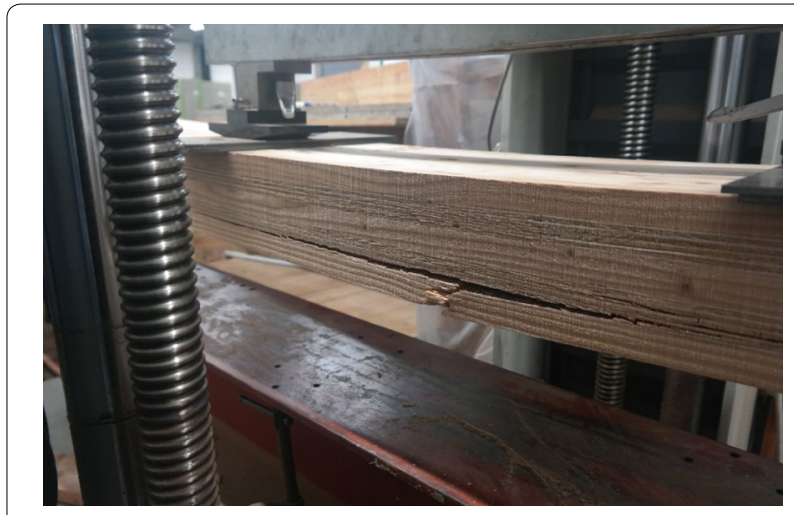

Fig. 5 Failure modes specimen of bending test (span-to-depth ratio was 25:1)

Table 2 Specification and load-carrying capacity of cross-laminated timber

\begin{tabular}{|c|c|c|c|c|c|c|c|}
\hline \multirow[t]{2}{*}{ Test type } & \multicolumn{5}{|l|}{ Dimensions (mm) } & \multicolumn{2}{|l|}{ Failure mode } \\
\hline & Thickness (thickness of lamina) & Width & Length & Test span & $a^{a}$ & Bending (\%) & $\begin{array}{l}\text { Rolling } \\
\text { shear } \\
(\%)\end{array}$ \\
\hline Shear test $\left(R_{s d}{ }^{b}: 12 / 1\right)$ & $123(25 / 24 / 25 / 24 / 25)$ & 300 & 1600 & 1476 & 615 & 52 & 48 \\
\hline Bending test $\left(R_{\text {sd }}: 25 / 1\right)$ & $123(25 / 24 / 25 / 24 / 25)$ & 300 & 3200 & 3075 & 615 & 100 & 0 \\
\hline
\end{tabular}

\footnotetext{
${ }^{a}$ Distance between external support and load application point

b Span-to-depth ratio
} 
Table 3 Comparisons of measured and predicted values of Ply-lam

\begin{tabular}{|c|c|c|c|c|c|c|}
\hline \multirow[t]{3}{*}{ Structural property } & \multicolumn{3}{|l|}{ Shear test } & \multicolumn{3}{|l|}{ Bending test } \\
\hline & \multirow[t]{2}{*}{ Measurement } & \multicolumn{2}{|l|}{ Prediction } & \multirow[t]{2}{*}{ Measurement } & \multicolumn{2}{|l|}{ Prediction } \\
\hline & & $\begin{array}{l}\text { By } \\
\text { reference } \\
\text { value }\end{array}$ & By tested value & & $\begin{array}{l}\text { By } \\
\text { reference } \\
\text { value }\end{array}$ & By tested value \\
\hline \multicolumn{7}{|l|}{ Bending stiffness $\left(10^{12} \times \mathrm{N} \mathrm{mm}^{2}\right)$} \\
\hline Average value & & & & $0.48^{\mathrm{a}}$ & $0.40^{b}$ & \\
\hline Difference $^{c}$ & & & & & $16.7 \%$ & \\
\hline \multicolumn{7}{|l|}{ Moment capacity $\left(10^{6} \times \mathrm{N}\right.$ mm) } \\
\hline 5th percentile value & & & & $14.6^{\mathrm{d}}$ & $5.2^{e}$ & $13.7^{f}$ \\
\hline Difference & & & & & $64.4 \%$ & $6.2 \%$ \\
\hline \multicolumn{7}{|l|}{ Shear capacity (kN) } \\
\hline 5th percentile value of measured data & $51.6^{9}$ & $48.0^{h}$ & $55.8^{i}$ & & & \\
\hline Difference & & $7.0 \%$ & $-8.1 \%$ & & & \\
\hline 5th percentile value by CMLE & $62.4^{j}$ & 48.0 & 55.8 & & & \\
\hline Difference & & $23.1 \%$ & $10.6 \%$ & & & \\
\hline \multicolumn{7}{|c|}{ average value of experimental data measured by Eq. 2} \\
\hline \multicolumn{7}{|c|}{ b Predicted value by transformed section of Ply-lam from Eq. 3} \\
\hline \multicolumn{7}{|c|}{ c Difference between measured and predicted value: (measured value - predicted value)/measured value $\times 100$} \\
\hline \multicolumn{7}{|c|}{ d 5 th percentile value of experimental data measured by Eq. 4} \\
\hline \multicolumn{7}{|c|}{ e Predicted value by Eq. 5 and reference value of No. 3 visual grade timber in Korean Design Standard in Table 1} \\
\hline \multicolumn{7}{|c|}{ f Predicted value by Eq. 5 and 5th percentile value of No. 3 visual grade timber in experimental data in Table 1} \\
\hline \multicolumn{7}{|c|}{ gth percentile value of experimental data measured by Eq. 6} \\
\hline \multicolumn{7}{|c|}{ h Predicted value by Eq. 8 and rolling shear strength of plywood in Korean Design Standard in Table 1} \\
\hline \multicolumn{7}{|c|}{ i Predicted value by Eq. 8 and rolling shear strength of plywood in experimental data in Table 1} \\
\hline j 5 th percentile value by censored maximum & relihood evaluation & ending failure & as counted as a cens & d data) & & \\
\hline
\end{tabular}

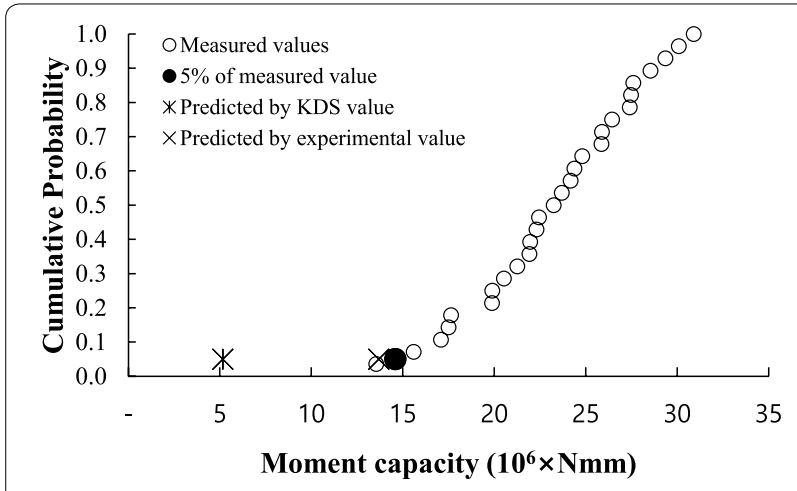

Fig. 6 Comparisons of measured and predicted moment capacity of Ply-lam

\section{Shear capacity of Ply-lam}

To measure the shear capacity of Ply-lam, the Ply-lam was tested according to the CLT shear test configuration in EN 16351 [14]. Table 2 shows the configuration of specimen and failure modes for the shear test as well as the bending test. Figure 7 shows the failure of Plylam in the shear test. For specimens with $R_{\text {sd }}$ of $12: 1$, rolling shear failure (Fig. 7a) or bending failure (Fig. 7b) occurred. Rolling shear failure occurred in 14 of 29 specimens (Fig. 7b) and bending failure occurred in 15 of 29 specimens. Approximately $52 \%$ of bending failure in shear test ( $R_{\mathrm{sd}}$ of 12:1) according to EN 16351 means that this test configuration was not suitable for Ply-lam. In other words, the shear capacity of Ply-lam was reinforced by plywood compared to typical CLT, and the $R_{\text {sd }}$ needs be shortened to induce shear failure in Ply-lam. The reason is that the bending failure occurred prior to the shear failure, at the lower force level than shear failure would occur. As the span-to-depth ratio decreases, the probability of bending failure drops down and the more specimens will fail by correct failure mode, shear failure.

In case of the rolling shear failure specimens, rolling shear failure occurred in plywood layer due to the lower rolling shear strength of plywood than the longitudinal shear strength of structural timber on the neutral line. This shows that the assumption based on the rolling shear strength of plywood to predict the shear capacity of Plylam was reasonable. In addition, in this study, the maximum shear stress point of Ply-lam was assumed to be at the axis just above the middle structural timber layer. In the shear test, rolling shear failure occurred at the center of plywood layer like Fig. $7 \mathrm{a}$ in some specimens. As the 


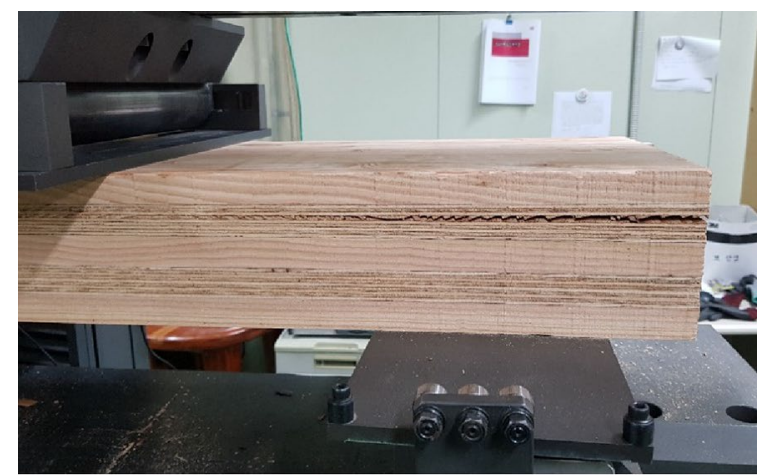

a Rolling shear failure

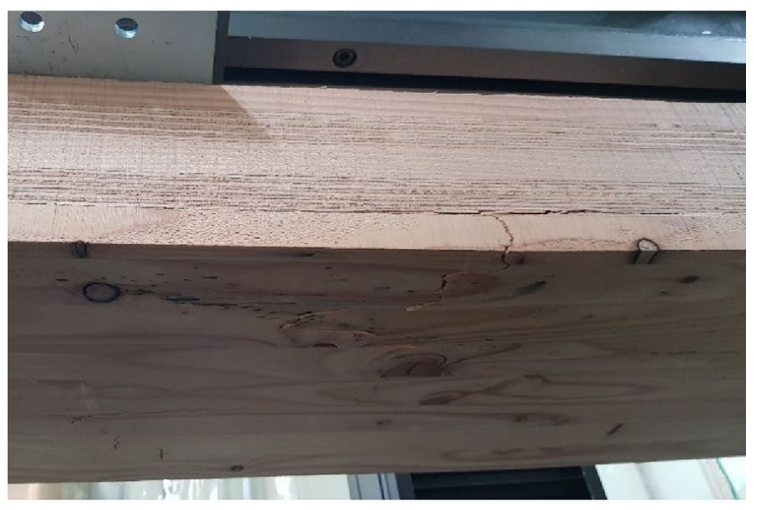

b Bending failure

Fig. 7 Failure modes in specimens with low span-to-depth ratio $(12: 1)$

distance between the maximum shear stress point and the neutral axis increases, static moment of area become smaller, and predicted shear capacity of Ply-lam become bigger. Therefore, this assumption was also appropriate from the point of view of predicting a low characteristic value of structural member for the safe design.

The predicted 5th percentile shear capacity of Ply-lam was compared with the measured values. Table 3 shows the 5 th percentile value of measured and predicted shear capacity. The first predicted value from reference rolling shear strength in standard $\left(V_{\text {predicted,standard }}\right)$ was $48.0 \mathrm{kN}$ (Table 3). The second predicted value from experimental 5 th percentile value $\left(V_{\text {predicted,standard }}\right)$ was $55.8 \mathrm{kN}$. The 5 th percentile of measured value $\left(V_{\text {measured }}\right)$ was $51.6 \mathrm{kN}$, and $7.0 \%$ higher than the first predicted value. However, it was $8.1 \%$ lower than the second predicted value.

In the shear test, about $52 \%$ specimens failed between the two load points in Fig. 8. There are two failure possibilities: failure by the normal stress under moment and failure by the shear stress. The short span test, in which span-to-depth ratio was 12:1, was intended to measure shear capacity of the specimen. But the $52 \%$

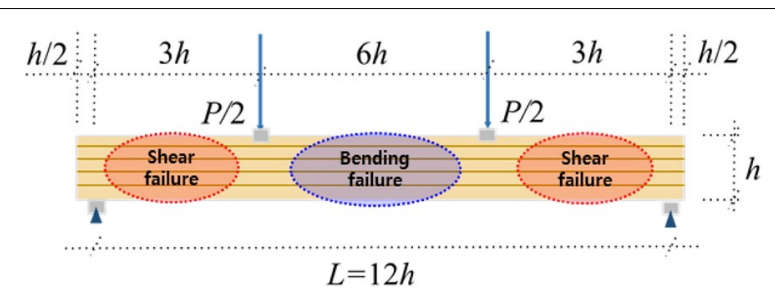

Fig. 8 Bending and rolling shear failure in shear test. $h$ thickness of specimen $(\mathrm{mm}), P$ load $(\mathrm{N}), L$ span of specimen $(\mathrm{mm})$

specimens failed by the normal stress induced by maximum moment occurred in loading span. This means that moment was more critical than shear in the test condition, and the actual shear capacity must be higher than the measured capacity in the CLT test condition. The 5th percentile shear capacity can be underestimated unless a specific analysis approach was applied in data analysis. The measured load capacity of bending failure specimen was considered as a censored data to derive more accurate shear capacity distribution by Censored Maximum Likelihood Evaluation (CMLE).

\section{Shear capacity of Ply-lam by censored data analysis}

In case of structural timber product test, different failure modes within the same test happen and the test results enclose an additional information. The underestimated data by different failure mode (weak zone) can be regarded as a censored data, and CMLE can be applied to derive the cumulative distribution function (CDF) of timber properties [32]. Weibull distribution was used to derive CDF from CMLE in this study, because Weibull distribution is often used for brittle failure and fatigue failure [33, 34]. The shape and scale parameter of Weibull distribution $(\alpha$ and $\beta$ ) were derived from maximizing two likelihood functions (Eq. 8). The first function uses the information that $k$ shear forces which failed by shear. The second function uses the information that $n-k$ shear forces $\left(s_{i}\right)$ which are under-measured by other failure mechanisms (bending failure). The first likelihood function is defined as by PDF (Weibull distribution with $\alpha$ and $\beta$ parameters). The second likelihood function is the probability function which has higher shear force than the measurement, $1-F\left(s_{i} \mid \alpha, \beta\right)$ with the same parameters $(\alpha$ and $\beta$ ). The optimal distribution parameters can be found by solving the maximization problem. The 5th percentile value was derived by Eq. 9 with the optimized parameters:

$$
\alpha, \beta=\max \left(\prod_{i=1}^{k} f\left(x_{i} \mid \alpha, \beta\right), \prod_{i=1}^{n-k}\left(1-F\left(s_{i} \mid \alpha, \beta\right)\right),\right.
$$




$$
\text { 5th percentile }=F^{-1}(\alpha, \beta, 0.05),
$$

where $\alpha$ and $\beta$ are the shape and scale parameters for Weibull distribution; $f\left(x_{i} \mid \alpha, \beta\right)$, probability density function for exactly observed data; $k$, the number of exactly observed data; $x_{i}$, the shear force of $i$ th specimen which failed by rolling shear; $F\left(s_{i} \mid \alpha, \beta\right)$, the cumulative distribution function for under-measured data (censored data); $s_{i}$, the shear force of $i$ th specimen which failed by bending (censored data); and $n$, the number of specimens.

The cumulative distribution of shear test specimen is presented in Fig. 9a according to the failure modes. The line in Fig. 9a, b shows the distribution fitted by CMLE. Several 5th percentile values derived from measured and predicted values for shear capacity (Table 3 ) are presented in Fig. 9b. The 5th percentile value determined by the CMLE was $62.4 \mathrm{kN}$. This value was approximately $20 \%$ higher than the measured value without censored data analysis $(51.6 \mathrm{kN})$. The 5 th percentile value of shear capacity by CMLE showed 10.6\% higher than the prediction based on the experimentally measured rolling shear strength $(55.8 \mathrm{kN})$. It also showed $23.1 \%$ higher than the prediction based on the reference value in standard (48.0 $\mathrm{kN})$. This result seems to indicate that the prediction method for shear capacity based on the CLT methodology was also adaptable as well as the bending properties. Unfortunately, in this study, the $52 \%$ of specimens failed by unintended failure (bending failure). The further researches on the statistical method for unintended failure and rolling shear capacity prediction for Ply-lam are required.

\section{Conclusions}

In this study, the structural properties of Ply-lam for a slab design were predicted and validated by comparing with experimental data. The measured bending stiffness and moment capacity were $16.7 \%$ and $6.2 \%$ higher than the predicted values, respectively. These results indicate that the prediction method for typical cross-laminated timber was also suitable for Ply-lam.

In rolling shear test, $52 \%$ specimens failed by bending, which was not intended. In this study, the span-to-depth ratio (12:1) for measuring the shear strength of typical CLT was applied. Thus, the span-to-depth ratio needs to be reduced for Ply-lam. These results indicate that the CLT can be reinforced by replacing the cross layer with plywood.

\section{Acknowledgements}

This study was conducted with the support of the 'R\&D Program for Forest Science Technology (Project No. 2017049A00-1919-BB02)' provided by the Korea Forest Service (Korea Forestry Promotion Institute).
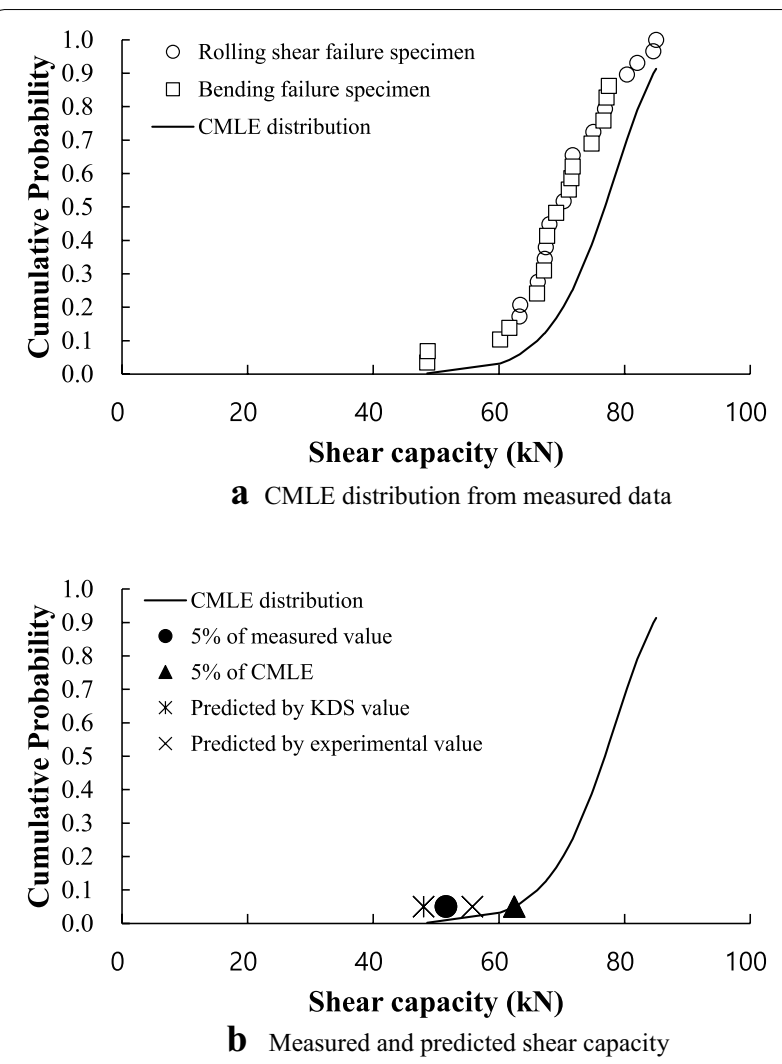

Fig. 9 Comparisons of measured and predicted shear capacity of Ply-lam

\section{Authors' contributions}

S-JP analyzed the data and wrote this manuscript. H-JL designed experimental setup and performed the experimental test. SMY designed the materials and controlled the manufacturing. SGK developed main material, Ply-lam. J-KO designed this research project, managed this research. All authors read and approved the final manuscript.

\section{Funding}

This project funded by Korea Forest Service (Korea Forestry Promotion Institute).

\section{Availability of data and materials}

All data generated or analysed during this study are included in this published article.

\section{Competing interests}

The authors declare that they have no competing interests.

\section{Author details}

${ }^{1}$ Research Institute of Agriculture and Life Sciences, Seoul National University, Gwanak-ro 1, Gwanak-gu, Seoul, Republic of Korea. ${ }^{2}$ Department of Forest Sciences, Seoul National University, Gwanak-ro 1, Gwanak-gu, Seoul, Republic of Korea. ${ }^{3}$ Department of Bio-based Materials, Chungnam National University, 99 Daehak-ro, Yuseong-gu, Daejeon, Republic of Korea. ${ }^{4}$ Research Institute of Agriculture and Life Sciences/Department of Forest Sciences, Seoul National University, Gwanak-ro 1, Gwanak-gu, Seoul, Republic of Korea.

Received: 11 September 2019 Accepted: 14 December 2019

Published online: 23 December 2019 
References

1. Piazza M, Zanon P, Loss C (2015) Timber structures. In: Manfredi G, Dolce $M$ (eds) The state of Earthquake Engineering Research in Italy: the ReLUISDPC 2010-2013 Project, Doppiavoce, Napoli, Italy, pp. 143-172. http:// dx.doi.org/10.14599/r101304

2. Loss C, Piazza M, Zandonini R (2016) Connections for steel-timber hybrid prefabricated buildings Part II: innovative modular structures. Constr Build Mater 122:796-808

3. Jones K, Stegemann J, Sykes J, Winslow P (2016) Adoption of unconventional approaches in construction: the case of cross-laminated timber. Constr Build Mater 125:690-702

4. Oh JK, Lee JJ, Hong JP (2015) Prediction of compressive strength of crosslaminated timber panel. J Wood Sci 61:28-34

5. Pang SJ, Jeong GY (2018) Load sharing and weakest lamina effects on the compressive resistance of cross-laminated timber under in-plane loading. J Wood Sci 64:538-550

6. Wallner-Novak M, Koppelhuber J, Pock K (2014) Cross-laminated timber structural design-basic design and engineering principles according to Eurocode. proHolzAustria, Vienna

7. Gagnon S, Pirvu C (2011) CLT handbook: cross-laminated timber. FPInnovations, Vancouver

8. Nairn JA (2017) Cross laminated timber properties including effects of non-glued edges and additional cracks. Eur J Wood Wood Prod 75:973-983

9. Parvizi A, Garrett KW, Bailey JE (1978) Constrained cracking in glass fiberreinforced epoxy cross-ply laminates. J Mater Sci 13:195-201

10. Nairn JA (1989) The strain energy release rate of composite microcracking: a variational approach. J Compos Mater 23:1106-1129

11. Choi C, Yuk CR, Yoo JC, Park JY, Lee CG, Kang SG (2015) Physical and mechanical properties of cross laminated timber using plywood as core layer. J Korean Wood Sci Tech 43:86-95

12. Choi C, Kojima E, Kim KJ, Yamasaki M, Sasaki Y, Kang SG (2018) Analysis of mechanical properties of cross-laminated Timber (CLT) with plywood using Korean larch. BioResources 13:2715-2726

13. Chang SJ, Wi S, Lee J, Lee $H_{1}$ Cho H, Kim S (2017) Analysis of cooling and heating energy demands of wooden houses with cross-laminated Timber (CLT) using domestic plywood as core materials. J Korean Soc Living Environ Sys 24:752-759

14. BS EN 16351:2015 (2015) Timber structures—cross laminated timberrequirements. BSI Standards Publication, London

15. Sikora KS, McPolin DO, Harte AM (2016) Effects of the thickness of crosslaminated timber (CLT) panels made from Irish Sitka spruce on mechanical performance in bending and shear. Constr Build Mater 116:141-150

16. Pang SJ, Jeong GY (2019) Effects of combinations of lamina grade and thickness, and span-to-depth ratios on bending properties of crosslaminated timber (CLT) floor. Constr Build Mater 222:142-151
17. He M, Sun X, Li Z (2018) Bending and compressive properties of cross laminated timber (CLT) panels made from Canadian hemlock. Constr Build Mater 185:175-183

18. ANSI/APA PRG 320-2018 (2018) Standard for performance-rated crosslaminated timber. The Engineered Wood Association, Tacoma

19. AWC (2015) National design specification for wood construction. American Forest and Paper Association, Washington, DC

20. Karacabeyli E, Douglas B (2013) Chapter 3 structural. In: CLT handbook: cross-laminated timber US edition, FPInnovations, Pointe-Claire, p. 8

21. Blass HJ, Fellmoser P (2004) Design of solid wood panels with cross layers. In: 8th world conference on timber engineering, vol. 14. pp. 543-548

22. Christovasilis IP, Brunetti M, Follesa M, Nocetti M, Vassallo D (2016) Evaluation of the mechanical properties of cross laminated timber with elementary beam theories. Constr Build Mater 122:202-213

23. ASTM D143-14 (2014) Standard test methods for small clear specimens of timber. ASTM International, West Conshohocken

24. NIFoS notification No. 2018-8 (2006) Standard and specification of wood products - structural lumber. National Institute of Forest Science, Seoul

25. BS EN 408-2010 (2010) timber structures - structural timber and gluelaminated timber. BSI Standards Publication, London

26. KDS 413302 (2016) Wood structure material and allowable stress. Korean Construction Standards Center, Goyang

27. Park CY, Pang SJ, Park JS, Kim KM, Park MJ, Lee JJ (2010) Study of the distribution properties and LRFD code conversion in Japanese larch. J Korean Wood Sci Tech 38:94-100

28. Oh SC (2018) Planar (rolling) shear strength of structural panels using 5-point bending test. J Korean Wood Sci Tech 46:425-436

29. ISO 13910 (2005) Structural timber-characteristic values of strengthgraded timber-sampling, full-size testing and evaluation. International Organization for Standardization, Geneva

30. Australian/New Zealand Standard 4063.2 (2010) Characteristic of structural timber part 2: determination of characteristic values. Standards New Zealand, Wellington

31. Barrett JD, Lau W (1994) Canadian lumber properties. Canadian Wood Council, Ottawa

32. Steiger R, Köhler J (2005) Analysis of censored data-examples in timber engineering research. In: Proceedings of CIB W. p. 18

33. Weibull W (1939) A statistical theory of the strength of materials. Royal Swedish Institute for Engineering Research, Stockholm

34. Bolotin WV (1969) Statistical methods in structural mechanics. HoldenDay, San Francisco

\section{Publisher's Note}

Springer Nature remains neutral with regard to jurisdictional claims in published maps and institutional affiliations.

\section{Submit your manuscript to a SpringerOpen ${ }^{\circ}$ journal and benefit from:}

- Convenient online submission

- Rigorous peer review

- Open access: articles freely available online

- High visibility within the field

Retaining the copyright to your article

Submit your next manuscript at springeropen.com 